\title{
MUCINOUS ADENOCARCINOMA OF APPENDIX PRESENTING AS ENTEROCUTANEOUS FISTULA IN RIGHT GROIN: RARE CASE REPORT AND REVIEW OF LITERATURE
}

\author{
Avinash Vishwani ${ }^{1}$, Rajesh Sharma ${ }^{2}$, Kiran Somani ${ }^{3}$, Manoj Kela ${ }^{4}$, Akshay Sharma $^{5}$.
}

1. Assistant Professor, Department of General Surgery, Shri Aurobindo Medical College and Post Graduate Institute, Indore, Madhya Pradesh.

2. Associate Professor, Department of General Surgery, Shri Aurobindo Medical College and Post Graduate Institute, Indore, Madhya Pradesh.

3. Professor, Department of General Surgery, Shri Aurobindo Medical College and Post Graduate Institute, Indore, Madhya Pradesh.

4. Associate Professor, Department of General Surgery, Shri Aurobindo Medical College and Post Graduate Institute, Indore, Madhya Pradesh.

5. 2ND Year Resident, Department of General Surgery, Shri Aurobindo Medical College and Post Graduate Institute, Indore, Madhya Pradesh.

\section{CORRESPONDING AUTHOR}

Dr. Avinash Vishwani,

90, Jairampur Colony,

Indore, Madhya Pradesh.

Email- avishwani@yahoo.com

\section{HOW TO CITE THIS ARTICLE:}

Avinash Vishwani, Rajesh Sharma, Kiran Somani, Manoj Kela, Akshay Sharma. "Mucinous Adenocarcinoma of Appendix Presenting as Enterocutaneous Fistula in Right Groin: Rare Case Report and Review of Literature". Journal of Evolution of Medical and Dental Sciences 2013; Vol2, Issue 24, June 17; Page: 4282-4286.

ABSTRACT: A 60 years old women presented with non healing wound in right groin since last 8 months. She had a history of incision and drainage of anterior abdominal wall abscess in right groin 1 year back, CT Scan demonstrated a mass in right iliac fossa and para renal space with possibility of ruptured appendix with periappendiceal abscess in retroperitoneum. In view a palpable lump a sinogram was performed suggestive of enterocutaneous colonic fistula. Right Hemicolectomy with fistulous tract excision was performed and Histopathology report was suggestive of Mucinous adenocarcinoma of appendix and caecum infiltrating through whole thickness of wall into pericaecal tissue. Stage- T3NxMx, with clear resection margins.

KEYWORDS: Adenocarcinoma mucinous appendix, enterocutaneous fistula, right hemicolectomy, anterior abdominal wall abscess

INTRODUCTION: Primary adenocarcinoma of appendix is an uncommon condition which constitute less than $0.5 \%$ of all gastrointestinal neoplasms. These tumours mostly present as acute appendicitis and have propensity to form fistulous communications with adjacent viscera like urinary bladder presenting as vesico-appendiceal fistula or to the anterior abdominal wall, presenting as anterior abdominal wall abscess or to skin presenting as an enterocutaneous fistulae. We report an unusual 
case of appendiceal adenocarcinoma presenting as an enterocutaneous colonic fistulae secondary to incision and drainage for anterior abdominal wall abscess.

\section{CASE REPORT:}

- 60 year old female patient admitted with complaint of a non healing wound in right groin region since last 8 months. Patient had a history of incision and drainage of abscess in right iliac fossa at other center one year back (details of surgery were not avilable). 2 months after the surgery, patient started having pus discharge from an opening at lateral end of scar of previous surgery. Occasionally she had history of discharge of some whitish sticky material from the wound. There was no history of fever, vomiting, loss of appetite, jaundice. There was no history of discharge of faecal matter from the wound. Patient was on full diet with normal bowel habits.

- On clinical examination there was a skin ulcer around $1 \mathrm{~cm}$ in diameter at lateral margin of a transverse scar in right groin with seropurulent discharge and hyper granulation tissue. There was also a tender, palpable lump in right iliac fossa of size $8 \mathrm{cms} * 6 \mathrm{cms}$. There were no signs of acute inflammation or peritonitis. Rest of abdomen was soft and there was no organomegaly. Her laboratory investigations revealed a Haemoglobin-11.1 mg\%, WBC count-11,100/mm3, Liver Function Tests -WNL, Pus C/S - Sterile , No growth seen till 72 hrs. Ultrasound was suggestive of RIF mass- ill defined with heterogenic hypoechoic area , Xray Chest- Normal

- $\quad$ CECT abdomen revealed an irregular shape 9.8x5.6x5.0 cms heterogenous mass in right iliac fossa and extending into right pararenal space predominantly with fluid content showing enhancing rim. Caecum is seen merging with the lump and terminal ileum seen abutted with this mass with slightly thickened bowel wall. Appendix is not seen separately. Tubular structure seen intermingled with this with tiny hyperdensity. Finding suggestive of possibility of ruptured appendix with periappendiceal abscess in retroperitoneum. Even oral and rectal contrast studies were unable to detect any fistulous communication with skin.

- Due to high suspicion of fistula a Sinogram was done which was suggestive of enterocutaneous colonic fistula

- With the clinical and radiological investigations differential diagnosis were made of either an appendicular perforation with abscess with resulting enterocutaneous fistula or Pott's Spine with psoas abscess or Ileocaecal tuberculosis with enterocutaneous fistulae. Appendicular neoplasm, in view of low incidence was kept last in the differential diagnosis.

- Exploratory Laparotomy was performed in which fistulous tract was seen communicating with caecum and ascending colon with extensive fibrosis in surrounding tissue and forming a mass in retroperitoneal area with pus inside that mass. There was no evidence of peritoneal dissemination. Rest of small intestine, transverse colon and descending colon were normal. Right hemi colectomy with excision of entire tract with ileo-transverse anastomosis was performed. Abdomen closed in layers. Patient stood procedure well. Resected part was sent for histo pathological examination

- Histopathology report revealed - Mucinous Adenocarcinoma - Appendix, infiltrating through whole thickness of wall into pericaecal tissue Stage- T3NxMx. 


\section{CASE REPORT}

Post operative period was uneventful; she was discharged after two cycles of chemotherapy of 5FU and Oxaliplatin.

DISCUSSION: Mucinous adenocarcinoma is rare carcinoma of appendix. An estimated 0.9-1.4\% [1,2] of all appendectomy specimens contain a neoplasm out of which majority are carcinoid while remaining 10-20\% are mucinous cystadenoma, adenocarcinoma, lymphosarcoma, paraganglioma. Frequency of appendiceal adenocarcinoma is $0.1 \%$, and constitutes less than $0.5 \%$ of all gastro intestinal malignant neoplasm [3]. This tumor produces mucus and invades in soft tissue and organs, grows faster more likely to get metastasis to L.N, liver and lungs. The usual presentation is that resembling acute appendicitis or that of a palpable lump in right iliac fossa. However it has also presented as pseudomyxoma peritonei, haematuria due to penetration of bladder, entero enteric colonic fistula, enterocutaneous fistula, retroperitoneal abscess, vaginal bleeding, hydronephrosis. The abnormal presentation of mucinous adenocarcinoma is due to its propensity for fistula formation due to invasion into surrounding structures [4].The patient in our case was probably operated for abdominal wall abscess at some other center. She came to us with unusual presentation of enterocutaneous fistula. There was a history of discharge of mucus like material coming from the wound at lateral margin of scar. We have come across only few cases reported till date of enterocutaneous fistula, secondary to mucinous adenocarcinoma appendix[5,6]. The point to be highlighted is the fact that abscesses in right lower abdomen should be thoroughly evaluated and unusual diagnosis of adenocarcinoma appendix should be kept in differential diagnosis for proper management of such a patient.

ACKNOWLEDGEMENT: We are thankful to Dr Vinod Bhandari, Chairman, Sri Aurobindo Medical College and Post Graduate Institute, Dr. S.D. Joshi, Dean, Dr. P.K.Banerjee, Professor and Head Department of Surgery for giving the permission to publish this case report.

\section{REFERENCES:}

1. Collins DC. 71,000 Human appendix specimens. A final report, summarizing forty years study. Am J Proctol 1963; 13:265-81.

2. Nitecki SS, Wilff BG, Schlinkert R, et al. The natural history of surgically treated primary adenocarcinoma of appendix. Ann Surg 1994; 219:51-7.

3. Lyss AP. Appendiceal malignancies. Semin Oncol $1988 ; 15$

4. Marcia L. McGory, Melinda A. Maggard, Hakjung Kang, Jessica B. O'Connell, Clifford Y. Ko. Malignancy of the Appendix: Beyond case series reports. Dis. Colon Rectum 2005; 48:22642271.

5. A Nakao, S Sato, A Nakashima, A Nabeyama, N Tanaka.Appendiceal Mucocele of Mucinous Cystadenocarcinoma with a cutaneous fistula. The Journal of International Medical Research 2002; 30:452-456.

6. Ito H,Utsunomiya $\mathrm{K}$, Murayama M,et al. A case of mucinous cystadenocarcinoma of the vermiform appendix with ileac and rectal fistula. J Jon Surg Assoc 1997; 58:855-9. 


\section{CASE REPORT}

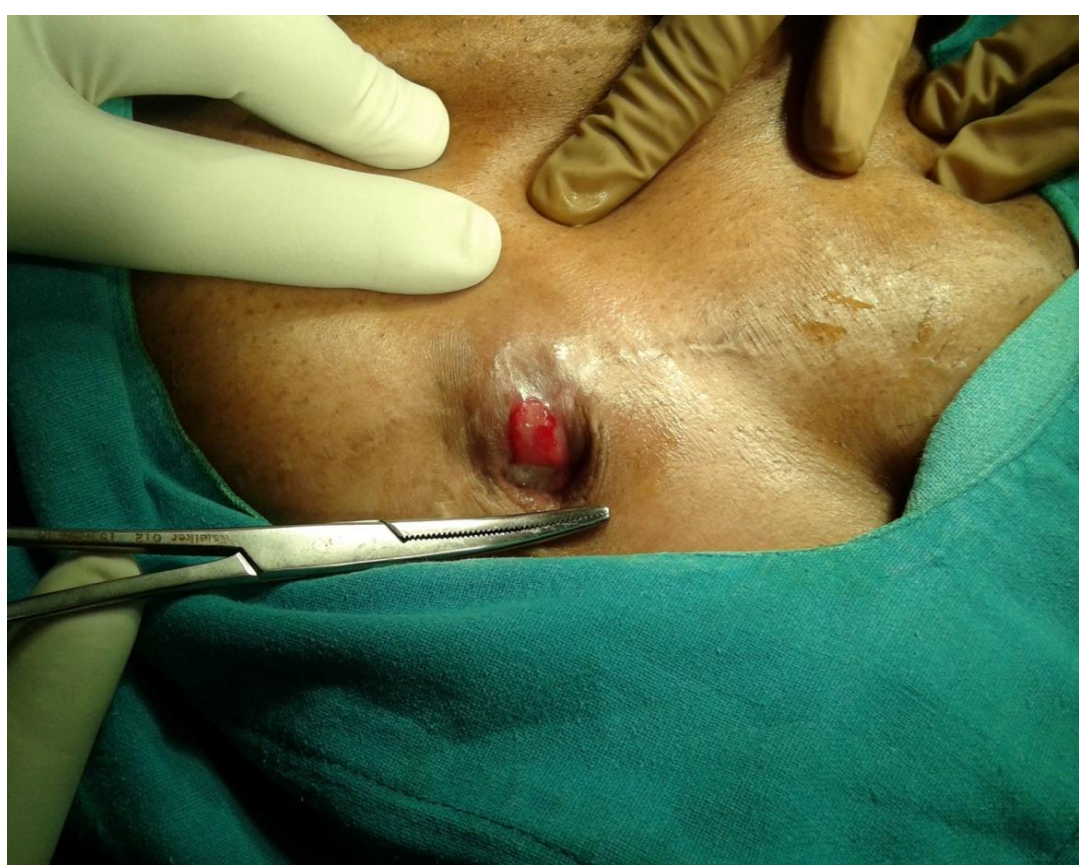

Figure 1 : Clinical photograph of patient showing nonhealing ulcer with hypergranulation at the lateral end of scar in right groin

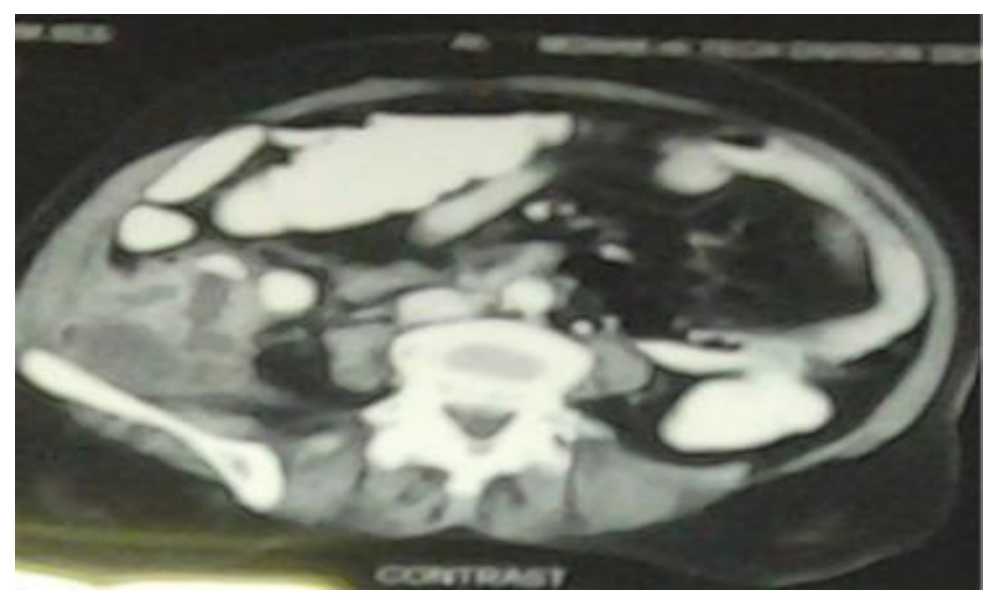

FIGURE 2: CECT Abdomen showing irregular mass in right iliac fossa with rim enhancement and fluid content with septation extending to retroperitoneum 


\section{CASE REPORT}

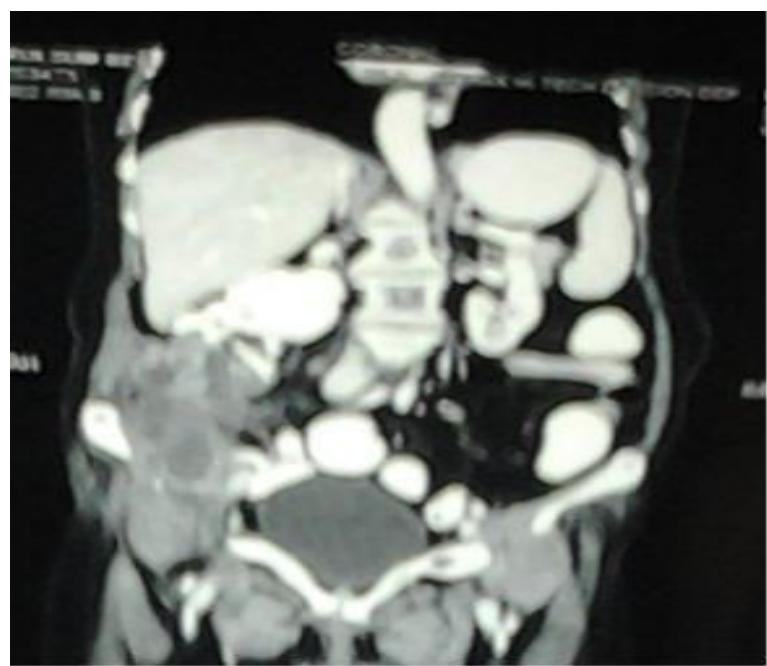

FIGURE 3: Heterogenous lump in right iliac fossa with retroperitoneal extension into right pararenal space

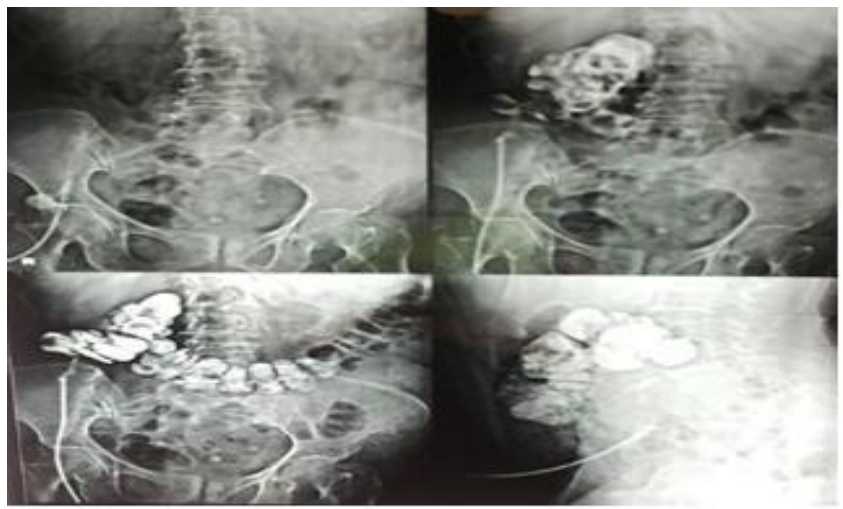

FIGURE 4; Sinogram revealing enterocutaneous colonic fistula

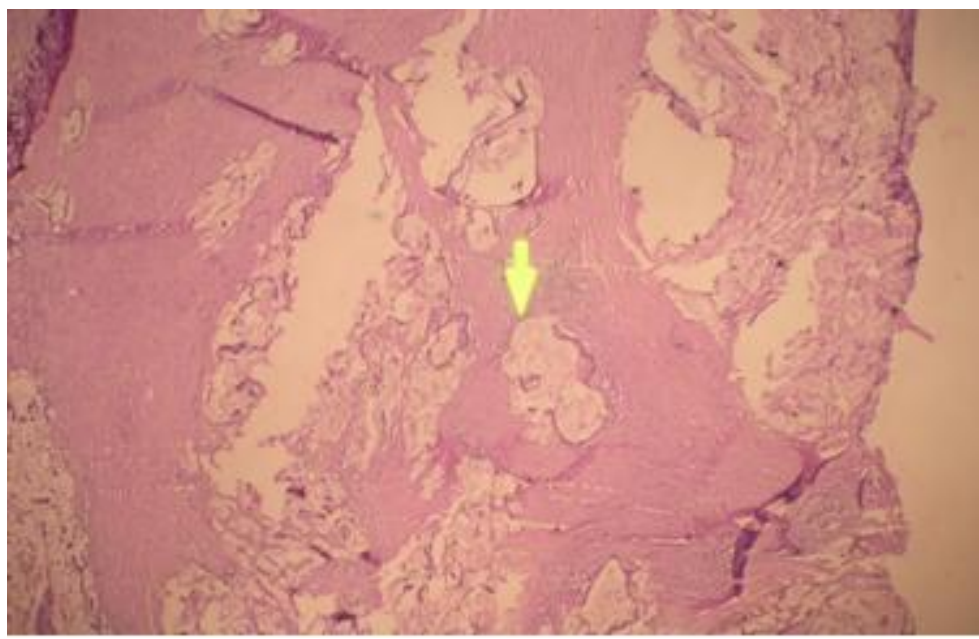

FIGURE 5: Histopathological Slides showing papillary pattern of epithelium progressively changing to a single layer of cells - as marked arrow. 